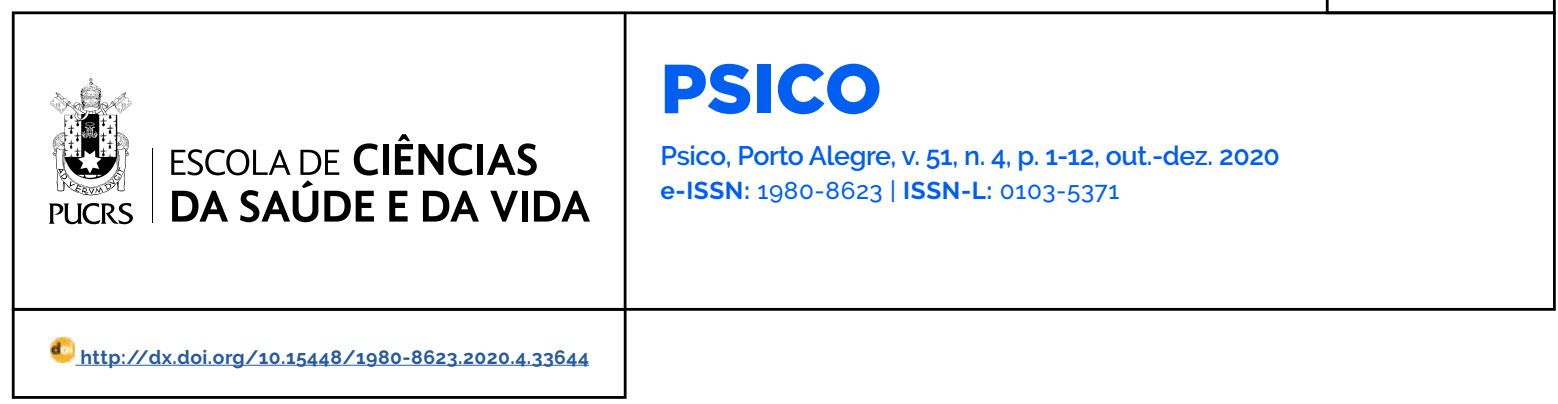

ARTIGO

\title{
Satisfação de vida, clima familiar e participação de crianças em atividades extracurriculares
}

\author{
Life satisfaction, family climate, and involvement of children in extracurricular activities \\ Satisfacción de vida, clima familiar y participación de niños en actividades extracurriculares
}

\section{Neyfsom Carlos \\ Fernandes Matias ${ }^{1}$}

orcid.org/0000-0001-9064-2282

neyfsom@ufsj.edu.br

Recebido em: 24 mar. 2019. Aprovado em: 14 set. 2020 Publicado em: 15 mar. 2021.

\section{(c) (1)}

Artigo está licenciado sob forma de uma licença Creative Commons Atribuição 4.0 Internacional.
Resumo: Trata-se de um estudo que investigou as relações entre as atividades extracurriculares, vinculadas ou não a programas de tempo integral, a satisfação de vida e o clima familiar de estudantes. Participaram da investigação 97 discentes de uma escola pública. Os participantes responderam ao Inventário do Clima Familiar para Crianças (ICF-C), a Escala Multidimensional de Satisfação de Vida para Crianças (EMSVC) e a uma Escala de Envolvimento em Atividades Extracurriculares (EEAE). Os resultados indicaram que os meninos se envolvem mais em atividades livres, enquanto as meninas realizam mais atividades acadêmicas/responsáveis e se vinculam mais com a escola. As ações ligadas ao programa de tempo integral garantem o direito à proteção social, bem como o acesso a atividades artísticas e recreativas, o que destaca a relevância do Estado investir em políticas públicas para a infância.

Palavras-chave: educação em tempo integral, programas após a escola, atividades extracurriculares, satisfação de vida, clima familiar

Abstract: It is a study that investigated relationships between extracurricular activities, whether or not linked to full-time programs, life satisfaction and the family climate of the students. Ninety-seven students from a public school participated in the study. Participants responded to the Family Climate Inventory for Children (ICF-C), the Multidimensional Life Satisfaction Scale for Children (EMSVC), and a Scale for Involvement in Extracurricular Activities (EEAE). The results indicated that boys engage more in free activities, while girls perform more academic/ responsible activities and become more involved with school. The actions linked to the full-time program guarantee the right to social protection, as well as access to artistic and recreational activities, which highlights the importance of the State investing in public policies for children.

Keywords: full-time education, after-school programs, extracurricular activities, life satisfaction, family climate

Resumen: Se trata de un estudio que investigó relaciones entre las actividades extracurriculares, vinculadas o no a programas de tiempo completo, la satisfacción de vida y el clima familiar de los estudiantes. Participaron en la investigación 97 alumnos de una escuela pública. Los participantes respondieron al Inventario del Clima Familiar para Niños (ICF-C), la Escala Multidimensional de Satisfacción de Vida para Niños (EMSVC) y una escala de Participación en Actividades Extracurriculares (EEAE). Los resultados indicaron que los niños se involucran más en actividades libres, mientras que las niñas realizan más actividades académicas/responsables y se vinculan más con la escuela. Las acciones vinculadas al programa de tiempo completo garantizan el derecho a la protección social, asi como el acceso a actividades artísticas y recreativas, lo que destaca la relevancia del Estado de invertir en políticas públicas para la infancia.

Palabras clave: educación a tiempo completo, programas después de la escuela, actividades extracurriculares, satisfacción de la vida, el clima familiar 
O desenvolvimento de programas públicos, complementares ao processo de escolarização, por meio de escolas e projetos de tempo integral, com foco na criança e no adolescente apresenta justificativas vinculadas às questões sociais e acadêmicas. Apesar de a última alegação ser o principal argumento para o oferecimento desses tipos de políticas públicas, nota-se que a escola tem se transformado em centros de cuidado e vem perdendo o status de instituição responsável pela disseminação do conhecimento (Coelho \& Mauricio, 2016; Schünemann \& Zukowski-Tavares, 2018). A opinião pública e o pensamento político de que a frequência em atividades esportivas, culturais e artísticas mantêm os estudantes fora de situações perigosas e ilicitas concordam com a necessidade desses programas de promover mais ações de proteção social (Batista \& Andrade, 2010; Castro \& Lopes, 2011). Não por acaso, os participantes e público-alvo dessas atividades provêm de grupos familiares de estratos sociais menos favorecidos (Matias, 2018).

Sabe-se que o background familiar tem implicações diretas no desenvolvimento humano (Ribeiro, Ciasca, \& Capelatto, 2016). Os programas desenvolvidos, antes ou após o período escolar, exercem papel não somente em questões sociais bem como de estímulo à aprendizagem de conteúdos acadêmicos. As estratégias de tempo integral, junto com a escola, complementam o papel da familia por meio do suporte ao desenvolvimento infantil a partir de políticas educacionais. É imprescindivel que o Estado desenvolva ações nesse sentido (Silva \& Silva, 2014; Soares, Brandolin, \& Amaral, 2017).

As familias dos estudantes participantes dessas ações têm inúmeros desafios na educação de seus filhos devido a questões econômicas e carecem de recursos promotores de três aspectos. O primeiro, diz respeito ao apoio à escolarização, que se refere ao suporte nas tarefas que colaboram com o desempenho escolar, por exemplo, a partir do acompanhamento e da definição de horário para que a criança faça a tarefa para casa. O segundo, trata do suporte ao desenvolvimento cognitivo traduzido em ações que o impulsionam, como a realização de passeios culturais e de lazer, promovendo um enriquecimento das interações sociais. Por fim, tem-se o suporte socioemocial, relacionado à qualidade da relação estabelecida com os pais, permeada pela harmonia, e que faz com que a criança se sinta amada e protegida (Andrada, Rezena, Carvalho, \& Benetti, 2008; D'Avila-Bacarji, Marturano, \& Elias, 2005).

Quando o Estado oferece programas como - Novo Mais Educação, atendendo às crianças dessas familias, ele colabora diretamente com dois desses suportes: o suporte à escolarização e o suporte ao desenvolvimento. O primeiro é contemplado quando os estudantes têm a oportunidade de ser auxiliados na realização tarefa de casa, ou seja, recebem apoio pedagógico e na elaboração de trabalhos escolares (Brasil, 2016). O segundo acontece por meio da realização de passeios, como visita a museus e exposições, frequentar teatros, e participar de atividades com seus pares, conduzidas por um adulto (D'Avila-Bacarji et al., 2005). Muitas dessas ações são oferecidas dentro de projetos de educação em tempo integral e isso é definido nas normativas que as orientam (Brasil, 2016, 2007).

Desde as Escolas Parque, promovidas por Anísio Teixeira na Bahia, os programas brasileiros de expansão da jornada escolar pautam-se em atividades extracurriculares (Coelho, 2009). O programa Novo Mais Educação oferecia atividades esportivas, artísticas e de lazer dentro e fora das escolas públicas (Brasil, 2016). Quando realizadas em espaços aquém das instituições de ensino, na maioria das vezes, eram feitas em parceria com Organizações Não Governamentais (ONGs) (Brasil, 2007). Ou seja, ao participar das ações extraclasses os estudantes recebiam suporte à escolarização e ao desenvolvimento, complementando o papel das familias.

Estudos sobre as interferências dessas atividades indicam efeitos positivos no desempenho escolar (Silva \& Ehrenberg, 2017; Osti, 2016; Soares, Riani, Nóbrega, \& Silva, 2014). Para além da escolarização, há apontamentos de que os estudantes que frequentam atividades esportivas, fora da escola, apresentam melhor 
aptidão física (Santos, Neto, \& Pimenta, 2013). Essas ações têm também o potencial para reduzir problemas comportamentais e aumentar as interações sociais (Vandell, Larson, Mahoney, \& Watts, 2014; Brandão \& Lordelo, 2017). Estudantes do sexo feminino valorizam esses tipos de atividades, principalmente, as que são voltadas para a escolarização pelo fato de entenderem que isso colaborará na sua formação (Carvalho, Senkesvicks, \& Loges, 2014). De certa forma, essa implicação acontece e elas se sobressaem na escola em relação aos colegas do sexo masculino (Carvalho, Loges, \& Senkesvicks, 2014). Assim, as atividades oferecidas fora do horário regular de ensino têm se transformado em contextos de desenvolvimento, colaborando não só com o desempenho escolar e desenvolvimento físico, como também na promoção das habilidades sociais e no aumento da satisfação de vida das crianças e dos adolescentes (Gilman, Meyers, \& Perez, 2004; Pierce, Bolt, \& Vandell, 2010).

Apontar que as atividades de tempo integral colaboram com o suporte de questões que a priori dizem respeito à família, significa destacar a necessidade de articulação entre escola, programas de tempo integral e familias. Essa articulação é um tanto quanto complicada e apresenta-se como extremamente delicada e dificil. Isso acontece devido à certa desconfiança tanto dos responsáveis como dos professores em relação ao papel desempenhado por cada um na educação das crianças, nas escolas como também no desenvolvimento de programas de tempo integral. No último caso, há indicações de que os educadores têm "visões deficitaristas das familias, segundo as quais se ressaltam condições de miséria e iniquidade e/ou de negligência" (Resende, Canaan, Reis, Oliveira, \& Souza, 2018, p. 437).

Essas situações, a partir da percepção dos profissionais envolvidos no trabalho com as crianças, conduzem à renúncia dos responsáveis dos seus deveres diante dos estudantes, outorgando à escola toda a obrigação de educá-los. Predomina o imaginário, por parte dos profissionais envolvidos na educação de tempo integral, de que no contexto familiar dos estudantes, participantes dessas ações, ocorrem processos negativos. Ou seja, as familias se organizam de forma precária e há um clima, em uma grande maioria delas, de aspectos ruins traduzidos na negligência dos pais em relação aos filhos. Não é demais destacar que essa inferência seja fruto de preconceitos por parte desses profissionais a partir da associação entre baixo nivel socioeconômico e problemas familiares (Cavaliere, Coelho, \& Maurício, 2013).

A forma como as ações recreativas e de lazer, proporcionadas por programas de ampliação da jornada escolar são desenvolvidas, aponta a possibilidade de seus participantes demonstrarem indices superiores de satisfação de vida (Oberle, Schonert-Reichl, \& Zumbo, 2011). Esse efeito acontece porque as atividades colaboram nesse sentido ao oferecer atividades de lazer em grupo, facilitando a interação social e o desenvolvimento de relações de amizade (Giacomoni, Souza, \& Hutz, 2016). Concomitantemente, por passarem mais de sete horas longe do contato com as suas famílias, é possivel que os participantes das atividades de tempo integral percebam o clima familiar de forma diferente dos não participantes.

As considerações apresentadas demonstram a possibilidade de interferências dos programas de tempo integral, além do desempenho escolar. Especificamente, aponta-se que há chance de as atividades extracurriculares promoverem suporte ao desenvolvimento que favoreceriam os processos de escolarização. Simultaneamente, a visão dos educadores indica a possibilidade de o ambiente familiar dos participantes dessas ações ser marcado por características negativas. Com isso, este estudo explora a possibilidade de a participação nas atividades de tempo integral influenciar aspectos diferentes do desempenho escolar e da proteção social. Assim, esse estudo teve o objetivo de pesquisar as relações entre as atividades extracurriculares, vinculadas ou não a programas de tempo integral, a satisfação de vida e o clima familiar dos estudantes. Especificamente, buscou-se: (a) identificar a existência de diferenças entre participantes e não participantes de um programa de ampliação da jornada escolar no envolvimento em atividades extracurriculares, na 
satisfação de vida e no clima familiar; (b) levantar possiveis diferenças nessas questões em relação ao sexo; e (c) verificar a existência de correlações entre a realização de atividades extracurriculares, o bem-estar subjetivo e o clima familiar.

\section{Método}

\section{Delineamento e participantes}

Trata-se de um estudo exploratório (Gil, 2002). A escolha desse desenho se deu pela possibilidade que ele apresenta de promover a familiaridade com temas pouco pesquisados e de levantar hipóteses a serem debatidas e apuradas em novos estudos. A pesquisa contou com 97 participantes, $42(43.30 \%)$ do sexo masculino e $55(56,70 \%)$ do sexo feminino, sendo 43 (44,30\%) alunos do $4 .^{\circ}$ ano e 54 (55.70\%) do $5 .^{\circ}$ ano do ensino fundamental I de uma escola pública de uma cidade do estado de Minas Gerais. A idade média deles era de 10 anos, com desvio-padrão de 0,61. 0 nível socioeconômico da instituição de ensino era abaixo de 2,00. Esse escore foi apurado pela Secretaria Municipal de Educação por meio do levantamento da renda dos membros da familia e da disponibilidade de itens no lar dos estudantes. Com isso, é possivel afirmar que os discentes da instituição pertenciam a grupos familiares de estratos sociais menos favorecidos.

Os estudantes foram divididos em três grupos, de acordo com as atividades frequentadas no horário alternado ao da escola. No Grupo I $(n=44$; $45,40 \%$ ), foram alocadas as crianças que não frequentavam as atividades extracurriculares de programas de tempo integral. Elas ficavam em casa acompanhadas de um adulto. No Grupo II ( $n=36 ; 37,10 \%$ ), constam os participantes do Programa Escola Integrada que oferecia atividades como oficinas de informática, percussão, artes, música e dança. Além disso, havia a realização de passeios a parques, teatros, cinemas e clubes. Isso tudo acontecia ao longo da semana, durante quatro horas no decorrer da tarde, sob a responsabilidade de educadores sociais. O programa não estabelecia formação específica desses profissionais para a condução das atividades que eram oferecidas dentro da escola (sala multiuso, de informática, de vídeo e quadra esportiva), em um espaço alugado pelo programa e na praça do bairro próximo à escola. Por fim, no Grupo III ( $n=17 ; 17.50 \%$ ), estão aqueles que participavam das atividades ofertadas por uma ONG. Essas ações eram o auxílio a tarefa de casa, reforço escolar, oficinas de artes manuais e educação física, desenvolvidas no periodo vespertino, de segunda a sexta-feira com a duração de quatro horas. Os moldes do atendimento eram semelhantes ao de uma escola regular, tanto que a educação física acontecia uma vez por semana e havia um recreio de 15 minutos entre as atividades. Os espaços usados para o atendimento eram salas com quadro-negro e carteiras, sala multiuso, pátio e quadra esportiva na sede da ONG. Os educadores tinham ensino médio completo, sendo isso uma exigência da instituição. $\mathrm{Na}$ Tabela 1, encontra-se a divisão dos participantes por atividades extracurriculares e por sexo.

Tabela 1 - Distribuição da amostra nos grupos por sexo e tempo médio de participação nas atividades

\begin{tabular}{|c|c|c|c|c|}
\hline Grupo & Masculino & Feminino & Total & Tempo (Anos) \\
\hline I & 22 & 22 & 44 & --- \\
\hline ॥ & 13 & 23 & 36 & $2,09(\mathrm{DP}=0,81)$ \\
\hline III & 07 & 10 & 17 & $2,21(\mathrm{DP}=1,43)$ \\
\hline Total & 42 & 55 & 97 & \\
\hline
\end{tabular}

Do total de participantes, 53 (54,60\%) frequentavam atividades extracurriculares vinculadas à ampliação da jornada escolar, sendo 20 (20,60\%) do sexo masculino e 33 (34,00\%) do sexo feminino. Em relação aos outros estudantes, 44 (45,40\%) ficavam em casa, não participavam das 
ações oferecidas pela escola e pela ONG, sob a responsabilidade de um adulto, na maioria das vezes, a mãe, sendo que $23,25 \%$ eram do sexo feminino. No Grupo II, concentrava-se a maioria dos alunos vinculados às ações de ampliação da jornada escolar.

\section{Instrumentos}

Foram utilizados três instrumentos. O primeiro foi a Escala Multidimensional de Satisfação de Vida para Crianças (EMSVC) (Giacomoni \& Hutz, 2008). A EMSVC, a partir de 50 itens, tem o objetivo de traçar o perfil da satisfação de vida das crianças pela escala total e em relação a seis construtos, a saber: (a) Self: possui dez itens, descrevendo o self com caracteristicas positivas no que se refere a relacionamentos, autoestima, demonstração de afeto, bom humor, dentre outras (ex. Eu sou alegre); (b) Self Comparado: agrupa oito itens, que contemplam a capacidade de se avaliar a partir dos outros em questões como amizade, lazer, satisfação de desejos e afetos (ex.: Meus amigos brincam mais do que eu).; (c) Não violência: contempla quatro itens, associados a comportamentos agressivos (ex.: Gosto de brigas); (d) Familia: contém 11 itens, que dizem respeito às caracteristicas harmônicas, afetivas, saudáveis e relacionais do ambiente familiar (ex:: Minha familia me faz feliz); (e) Amizade: fator com dez itens, que se associam aos relacionamentos interpessoais quanto à diversão, lazer e situações de apoio (ex.: Eu me divirto com meus amigos); e (f) Escola: possui sete itens, que destacam a importância e a satisfação com esse ambiente e no que se refere às relações pessoais concernentes a ele (ex.: Eu gosto de ir à escola). A resposta ao instrumento é por meio de escala Likert, com cinco pontos: (1) Nem um pouco; (2) Um pouco; (3) Mais ou menos; (4) Bastante; e (5 Muitíssimo. Para levantar características familiares, foi utilizado o Inventário do Clima Familiar para Crianças (ICF-C) (Matias \& Teodoro, 2018) que avalia o clima familiar compreendido a partir da maneira como as crianças percebem as relações estabelecidas nesse grupo. $O$ inventário contempla 18 itens, referentes às interações familiares positivas e negativas, divididas em dois fatores: clima negativo e clima positivo. O primeiro, com oito itens, relacionados a conflitos (ex:: as pessoas resolvem os problemas brigando); no segundo, estão os 10 itens relacionados ao auxilio mútuo e à união entre os membros da familia (ex.: existe união entre as pessoas). Nas respostas, dispostas em escala Likert, a criança tem que marcar uma entre as opções: (1) não concordo de jeito nenhum; (2) concordo um pouco; (3) concordo mais ou menos; (4) concordo muito; e (5) concordo completamente.

Por fim, foi aplicada a Escala de Envolvimento em Atividades Extracurriculares (EEAE) (Matias, 2019). Esse instrumento de autorrelato apura o envolvimento das crianças em atividades desenvolvidas fora da escola a partir de três fatores. $O$ primeiro se refere às atividades desestruturadas, livres e de lazer com 10 itens (ex:: brinco na rua), o segundo, com seis itens, às atividades extracurriculares estruturadas desenvolvidas por programas de ampliação da jornada escolar e/ou escolas especializadas (ex: faço aula de música) e, por fim, com sete itens, o terceiro fator trata de atividades acadêmicas/responsáveis (ex.: eu ajudo a arrumar a minha casa; faço o para casa). A resposta ao instrumento acontece a partir de uma escala do tipo Likert de três pontos: (1) sempre; (2) às vezes; e (3) nunca. Além dessas informações a EEAE apura, ainda, no cabeçalho, o nome, o sexo, o ano escolar, a data de nascimento e onde a criança fica quando não está na escola. Esse último item possui três opções de resposta: (1) Em casa. Com quem?; (2) No projeto. Qual?; e (3) Outro lugar. Qual?

\section{Procedimentos}

Todos os procedimentos seguiram as orientações da Resolução 466/2012 do Conselho Nacional de Saúde (Brasil, 2012) e o projeto de pesquisa foi aprovado por um comitê de ética (parecer n. ${ }^{\circ}$ 2.359.787). Os responsáveis pelas crianças autorizaram a participação delas, assinando o Termo de Consentimento Livre e Esclarecido, e elas consentiram em participar a partir do Termo de Assentimento Livre e Esclarecido.

O estudo foi conduzido em uma escola pública de uma cidade do estado de Minas Gerais. 
As avaliações foram realizadas em uma sala disponibilizada pela direção da instituição e de acordo com as normas prescritas pelos autores dos instrumentos, sem prejuizos às condições necessárias. As aplicações ocorreram em grupos de 7 a 10 estudantes.

A formação dos três grupos se deu a partir das informações coletadas pela EEAE. Por meio da investigação das datas de nascimento dos participantes, foram mantidos na pesquisa somente aqueles que demonstravam correspondência entre idade e ano escolar. Para confirmar a veracidade dos dados, foram enviadas listas com os nomes dos integrantes dos Grupos II e III para as coordenações das atividades extracurriculares a fim de comprovar a frequência e a vinculação das crianças. Além disso, elas informaram o tempo de participação dos estudantes nas ações. Crianças que ficavam sozinhas em casa ou que frequentavam outras atividades extracurriculares, oferecidas de segunda a sexta-feira, por exemplo, escolinhas de futebol e outras ONGs, foram retiradas da amostra devido à impossibilidade de formação de grupos com mais de cinco integrantes com elas. A secretaria da escola confirmou as datas de nascimento dos discentes. $O$ autor deste artigo, juntamente com um auxiliar, foi o responsável por toda a coleta de dados no campo.

\section{Análise dos dados}

Devido ao caráter ordinal dos dados, as análises foram realizadas a partir de testes não paramétricos. Com isso, foram usados os testes de Kruskal-Wallis, com medidas a posteriori com o teste $U$ de Mann-Whitney, e a correlação de Spearman. O nivel de significância adotado em todas as análises foi de $p<0,05$.

\section{Resultados}

Antes de comparar os grupos, foi investigada a existência de diferença entre os participantes divididos por sexo e ano de escolarização em todos os instrumentos. Houve diferença significativa em relação ao sexo no escore dos construtos Escola $(U=696,500 ; p=0,001)$ , da EMSVC, Atividades Desestruturadas $(U=627,500 ; p<0,001)$ e Atividades Acadêmicas/Responsáveis $(U=802,000 ; p=0,01)$ da EEAE, sendo que as meninas alcançaram postos mais altos na primeira e na terceira avaliação e, os meninos, na segunda. Ou seja, elas demonstraram maior envolvimento com a escola e com as atividades acadêmicas/responsáveis e eles com as atividades desestruturadas. Quanto ao ano de escolarização, foi detectado que os alunos do $4 .^{\circ}$ ano alcançaram postos mais altos no total da EMSVC $(U=807,000 ; p=0,010)$ e, os do $5 .^{\circ}$ ano, no envolvimento em Atividades Extracurriculares Desestruturadas ( $U=867,000 ; p=0,032$ ). Diante desses achados, foram realizadas análises entre os Grupos I, II e III, considerando apenas os participantes do $4 .^{\circ}$ ano no total da EMSVC, do $5{ }^{\circ}$ no envolvimento em Atividades Extracurriculares Desestruturadas, e somente do sexo feminino nos construtos Escola.

Nessas análises, foi encontrada significância estatística apenas no construto Escola entre os participantes do sexo feminino nos três grupos $\left(X^{2}=7,663 ; p=0,022\right)$ As medidas a posteriori, realizadas pelo teste $U$ de Mann-Whitney, indicaram a existência de diferença significativa entre os Grupos I e II ( $U=160,000 ; p=0,033)$, e I e III $(U=47,500 ; p=0,010)$. As alunas vinculadas à ONG demonstraram postos mais altos, seguidas das que frequentavam às atividades do Programa Escola Integrada e das não participantes das atividades extracurriculares. Destaca-se que não houve diferença entre as participantes vinculadas aos Grupos II e III. Na Tabela 2 estão as medianas e as médias alcançadas pelos participantes, os desvios-padrão e o valor de p obtido a partir das comparações entre os grupos. 
Tabela 2 - Medianas, Médias, desvios-padrão e resultados dos testes estatísticos dos três grupos

\begin{tabular}{|c|c|c|c|c|c|c|c|c|c|c|c|}
\hline \multirow[b]{3}{*}{ Avaliações } & \multicolumn{9}{|c|}{ Grupos } & \multirow[b]{3}{*}{$\chi^{2}$} & \multirow[b]{3}{*}{$p$} \\
\hline & \multicolumn{3}{|c|}{$\begin{array}{c}I \\
(n=46)\end{array}$} & \multicolumn{3}{|c|}{$\begin{array}{c}\text { II } \\
(n=36)\end{array}$} & \multicolumn{3}{|c|}{$\begin{array}{c}\text { III } \\
(n=17)\end{array}$} & & \\
\hline & $\mathrm{Md}$ & $M$ & DP & $\mathrm{Md}$ & $M$ & DP & $\mathrm{Md}$ & $M$ & $\mathrm{DP}$ & & \\
\hline Self & 3.95 & 3.93 & 0,60 & 3,90 & 3.93 & 0,62 & 3,90 & 3,84 & 0,62 & 0,344 & 0,84 \\
\hline Self-Comp. & 2,56 & 2,53 & 0,92 & 2,43 & 2,51 & 0,88 & 2,37 & 2,56 & 1,00 & 0,013 & 0,99 \\
\hline Não viol. & 2,00 & 2,21 & 1,15 & 2,00 & 2,25 & 1,10 & 2,00 & 2,07 & 0,81 & 0,087 & 0,98 \\
\hline Familia & 4,37 & 4,23 & 0,43 & 4,45 & 4,28 & 0,41 & 4,45 & 4,20 & 0,46 & 0,254 & 0,88 \\
\hline Amizade & 3.90 & 3,85 & 0,44 & 3,90 & 3.99 & 0,45 & 4,10 & 3,89 & 0,52 & 1,117 & 0,57 \\
\hline Escola & 4,21 & 3.99 & 0,87 & 4.57 & 4,24 & 0,77 & 4,71 & 4.50 & 0,56 & 4.958 & 0,08 \\
\hline EMSVC T. & 3,66 & 3,63 & 0,33 & 3,65 & 3,70 & 0,32 & 3,68 & 3,67 & 0,37 & 0,526 & 0,76 \\
\hline CF-Neg. & 14,00 & 16,05 & 5,82 & 16,00 & 17,36 & 7,67 & 16,00 & 16,69 & 4,00 & 0,516 & 0,77 \\
\hline CF-Pos. & 35.95 & 35,86 & 5.90 & 37,00 & 36,85 & 5,25 & 39,00 & 37,07 & 4,69 & 0,837 & 0,65 \\
\hline ICF-C T. & 53.50 & 51,91 & 7,37 & 53.50 & 54,22 & 8,90 & 53,00 & 53.77 & 5,72 & 0,664 & 0,72 \\
\hline EEAE-AD & 20,00 & 20,71 & 3.58 & 21,00 & 21,46 & 3,80 & 20,00 & 20,33 & 3,64 & 2,548 & 0,28 \\
\hline EEAE-AE & 8,00 & 7,96 & 1,84 & 9,81 & 9,50 & 2,25 & 9,00 & 9,10 & 1,87 & 12,471 & 0,002 \\
\hline EEAE-AAR & 16,31 & 16,26 & 2,76 & 18,00 & 17.59 & 2,73 & 17,00 & 16,38 & 2,48 & 5,468 & 0,06 \\
\hline Total EEAE & 44,68 & 44,94 & 5,78 & 49,00 & 48,56 & 5.91 & 44,00 & 45,82 & 6,32 & 6,941 & 0,03 \\
\hline
\end{tabular}

Notas. $\mathrm{Md}=$ Mediana. $\mathrm{M}=$ Média. $\mathrm{DP}=$ Desvio-padrão. Self-Comp. $=$ Self-Comparado. EMSVC T. = Escala Multidimensional de Satisfação de Vida para Criança Total. CF-NEG. = Clima Familiar Negativo. CF-Pos. Clima Familiar Positivo. ICF-C T = Inventário do Clima Familiar para Criança Total. EEAE = Escala de Envolvimento em Atividades Extracurriculares. $A D=$ Atividades Desestruturadas. $A E=$ Atividades Estruturadas. $A A R=$ Atividades Acadêmicas/Responsáveis.

Nas comparações entre os grupos foi encontrada diferença significativa, como é possivel observar na Tabela 1, a partir do teste de Kruskal-Wallis. Nas medidas a posteriori, com o teste $U$ de Mann-Whitney, observou-se que os participantes vinculados ao Programa Escola Integrada e da ONG se sobressairam em relação aos estudantes que não frequentavam as ações desses locais no fator 2 da EEAE. Ou seja, pelos resultados apurados nas comparações entre os Grupos I e II ( $U=450,000 ; p=0,001)$, I e III $(U=235,000 ; p=0,024)$ os discentes vinculados às atividades desenvolvidas pela escola e pela instituição social indicaram mais envolvimento em atividades estruturadas como aulas de dança, música e artes. Ainda em relação ao envolvimento em atividades extracurriculares, detectou-se significância estatística entre os Grupos I e II ( $U=525,500 ; p=0,010)$ no total da escala, sendo que os participantes das ações da Escola Integrada alcançaram postos mais altos, demonstrando que esses alunos realizavam mais atividades extracurriculares do que os que ficavam em casa, sob a responsabilidade de um adulto.

Em relação às análises de correlações, foi encontrada significância estatística em alguns aspectos. Foi observado a existência de correlação negativa entre o total da EEAE e o Self-Comparado $(r=-0,23 ; p=0,026)$. As análises indicaram, ainda, correlações positivas e negativas entre o envolvimento em atividades acadêmicas/responsáveis e os fatores Self $(r=0,31 ; p=0,002)$, Não violência $(r=-0,23 ; p=0,20)$ e Escola $(0,40 ; p=0,000)$. Houve, também, correlações positivas e negativas no envolvimento nessas atividades extracurriculares, e o clima positivo $(r=0,26 ; p=0,010)$ e o clima negativo $(r=-0,35 ; P=0,000)$ do ICF-C. 


\section{Discussão}

Este estudo explorou as relações entre as atividades extracurriculares, a satisfação de vida e o clima familiar de estudantes, participantes e não participantes de duas atividades extracurriculares vinculadas às estratégias de ampliação da jornada escolar de um município do estado de Minas Gerais. Os resultados apontaram ausência de diferença significativa entre os discentes divididos por atividades extracurriculares, na avaliação do clima familiar, no escore total e em cinco dos seis construtos da Escala Multidimensional de Satisfação de Vida para Crianças (EMSVC). Nas comparações entre o sexo feminino e o sexo masculino, foi observado que as meninas se envolvem mais com a escola e com as atividades acadêmicas/ responsáveis, enquanto os meninos se vinculam mais com as atividades desestruturadas.

As análises considerando os alunos divididos por sexo destacaram significância estatística no construto escola da EMSVC entre as meninas dos Grupos I e II e Grupos I e III. As estudantes vinculadas à ONG demonstraram postos mais altos, seguido das que ficavam no Programa Escola Integrada e das que não participavam de nenhuma atividade. Além desses dados, destacou-se, ainda, correlações, de magnitude fraca a moderada, entre o envolvimento em atividades extracurriculares acadêmicas/responsáveis com fatores relacionados à satisfação de vida e com o total da Escala de Envolvimento em Atividades Extracurriculares (EEAE) com o self-comparado. Atendendo aos objetivos do delineamento exploratório, esses resultados conduziram a elaboração de três hipóteses, debatias a seguir, com questões importantes para o estudo dos impactos das atividades extracurriculares.

A primeira é a de que nas familias dos participantes das atividades de tempo integral não predominam aspectos negativos. Dois aspectos, presentes nos contextos das atividades extracurriculares, como os frequentados por parte dos participantes neste estudo, se destacam como intervenientes nessa hipótese. O primeiro é de que os profissionais responsáveis por essas ações têm visões distorcidas em relação às familias no sentido de pensarem que essas não assumem a responsabilidade pelas crianças (Resende et al., 2018). Isso é traduzido nas queixas dos educadores de que os responsáveis outorgam à escola e aos projetos de tempo integral a responsabilidade pelo cuidado, educação das crianças e pela associação entre condição de miséria e iniquidade com negligência (Cavaliere et al., 2013).

O fato de haver uma relação entre a participação nesses tipos de atividades, sobretudo, nas desenvolvidas por ONGs, com o baixo nivel socioeconômico das famílias (Matias, 2018) colabora com essa visão. A ausência de diferença significativa nas avaliações sobre a percepção do clima familiar indica que nas famílias dos participantes das ações de tempo integral pode não predominar aspectos negativos como é apontado pelo senso comum. Além disso, existe a possibilidade dessas ações colaborarem indiretamente com as relações familiares por proporcionarem um local para as crianças ficarem enquanto os responsáveis trabalham e isso melhoraria a renda da familia (Resende et al., 2018). Consequentemente, tem-se a possibilidade do oferecimento de recursos às crianças que proporcionam ganhos cognitivos e socioemocionais.

Desta forma, o fator proteção constitui-se como o segundo aspecto que colabora na manutenção dos aspectos positivos do contexto familiar, o que justifica a ausência de diferença entre os grupos de participantes e não participantes das atividades extracurriculares promovidas pelos programas de tempo integral em relação ao clima familiar. Assim, ao atuar também no âmbito da proteção social (Brandão \& Lordelo, 2017), essas ações garantem a possibilidade de as familias buscarem recursos para a sua manutenção, bem como apoiam o processo de escolarização, por meio de diferentes atividades, e dão suporte ao desenvolvimento cognitivo (Andrada et al., 2008; D'Avila-Bacarji et al., 2005). Isso não exime as familias das suas responsabilidades quanto ao seu papel no desenvolvimento infantil. Porém, a condição de impossibilidade do cuidado diário devido à inserção no mercado de trabalho dos responsáveis destaca a importância desses pro- 
gramas. Não por acaso eles são desenvolvidos em regiões de vulnerabilidade social, como é o caso da pesquisa ora em tela. As evidências de sucesso escolar das crianças dos meios populares (Lahire, 2004) apontam que as familias desses contextos conseguem prover processos capazes de colaborar na escolarização de suas crianças. Porém, isso não acontece na mesma intensidade para os meninos e é no âmbito familiar que se destaca a origem da segunda hipótese do estudo, que trata das diferenças entre eles e as garotas no envolvimento nas atividades extracurriculares.

As interações familiares reforçam as diferenças de gênero ao outorgar às meninas tarefas acadêmicas/responsáveis e deixar os meninos mais livres para as brincadeiras. Essa hipótese surge a partir do dado de que há mais envolvimento delas em tarefas vinculadas ao cuidado de casa e acadêmicas, quando comparadas aos meninos; que, por sua vez, demonstram maiores escores nas atividades desestruturadas. Há uma tendência dos meninos se vincularem mais a essas atividades (Giacomoni et al., 2016). Ou seja, eles têm mais oportunidades de usar o tempo em atividades livres em casa, por exemplo, jogando videogame, brincando na rua, jogando futebol e assistindo à televisão (Senkevics \& Carvalho, 2015; Silva, Monteiro, Pontes, Magalhães, \& Silva, 2012).

As atividades acadêmicas/responsáveis acontecem predominantemente no contexto familiar. Nesse sentido, é possivel inferir que as familias promovem mais situações para o envolvimento das garotas nesses tipos de atividades do que para os meninos. Esse resultado já foi evidenciado em outros estudos (Nascimento \& Trindade, 2010; Senkevics \& Carvalho, 2015). A consequência da maior realização dessas tarefas é de que as meninas acabam se envolvendo mais com a escola, o que pode ser observado na diferença entre os sexos no construto Escola da EMSVC e entre os grupos.

As atividades da ONG lembravam uma escola, tanto que as estudantes vinculadas a essa ação demonstraram postos mais altos no construto Escola da EMSVC quando comparadas com as colegas dos outros grupos. Como elas ficam sobrecarregadas com as tarefas de auxilio na arrumação da casa, a escola passa a ser um contexto de interação social, sendo o local onde encontrarão as amigas e terão momentos de lazer. Isso colabora para o melhor desempenho escolar delas em relação aos meninos (Carvalho et al., 2014, 2016). Porém, essa situação reforça as diferenças de gênero da sociedade mantendo os homens como provedores e as mulheres sendo preparadas para o cuidado da casa desde a infância (Nascimento \& Trindade, 2010).

As informações dessas diferenças no envolvimento em atividades extracurriculares, que acontecem, principalmente, fora dos programas de tempo integral, conduziram a terceira hipótese apurada a partir dos dados. O estudo das implicações das atividades de tempo integral deve considerar o envolvimento em diferentes atividades, não se concentrando no que acontece nessas ações. Ou seja, é preciso ponderar os aspectos metodológicos que consigam abarcar informações para além dos programas em si. Nesse sentido, é importante conceber esse tipo de estudo também como uma investigação acerca do uso do tempo pelos estudantes fora da escola (Vandell et al., 2014). Com isso, torna-se pertinente a inclusão de estratégias para apurar o envolvimento em atividades para além das que são proporcionadas pelos programas, como as oferecidas por escolas especializadas, por exemplo, aulas de música, uma ou duas vezes por semana.

As correlações encontradas entre as atividades acadêmicas/responsáveis e os fatores Self. escola e não violência da EMSVC e com os dois fatores do ICF-C apontam questões importantes a serem consideradas. A definição de um horário para fazer a tarefa de casa, para estudar, e a orientação de que as crianças devem auxiliar na organização do lar podem ser aliados importantes no processo de escolarização. Isso colabora para o desenvolvimento do self com caracteristicas positivas (Giacomoni et al., 2016), bem como para o sentimento de que a escola é importante e que acontecem coisas boas nesse contexto. Da mesma forma, esse conjunto de atividades extracurriculares promove a percepção de que é preciso evitar a violência. 
As correlações significativas, positiva com o clima familiar positivo e negativo com o clima familiar negativo do ICF-C e as atividades acadêmicas/responsáveis, destacam que a disposição da família em estimular o envolvimento das crianças nesses tipos de tarefas colabora com um ambiente familiar favorável. Ao considerar que a satisfação de vida implica, entre outros aspectos, ter boas relações interpessoais no contexto familiar (Giacomoni et al., 2016) esse resultado indica o quanto o envolvimento nessas atividades pode influenciar o desenvolvimento infantil. Nesse sentido, torna-se pertinente o oferecimento de programas para pais com foco nessas atividades, tendo em vista o potencial da família para o desenvolvimento infantil (Ribeiro et al., 2016). Porém, é importante que as tarefas acadêmicas/responsáveis sejam estimuladas de forma equânime entre meninos e meninas pela possibilidade de ganhos no rendimento acadêmico (Osti, 2016). Apesar do estudo não abordar esse aspecto, é provável que, em pesquisas futuras, sejam destacadas correlações positivas entre o envolvimento nas atividades acadêmicas/ responsáveis e o desempenho escolar.

\section{Considerações finais}

Este estudo apontou que a visão de que nas familias de crianças que participam de atividades de tempo integral predominam aspectos negativos pode não ser real porque os programas colaboram de forma indireta com o clima familiar. Ao considerar o que é feito pelas crianças quando não estão na escola, notou-se indícios de que as familias estimulam mais as meninas nas atividades acadêmicas/responsáveis, deixando os meninos livres para as brincadeiras. Essas observações foram possiveis na medida em que o estudo considerou aspectos para além da participação nas ações de tempo integral.

Ao se dispor a investigar possiveis influências para além do desempenho escolar, o trabalho destacou a importância das atividades de tempo integral na proteção social de seus participantes. As atividades frequentadas pelos estudantes cumpriam o papel protetivo ao qual se propunham. Especificamente, no Programa Escola Integrada, destaca-se o oferecimento de oportunidades de visitas a espaços culturais como teatro, museus e parques aos estudantes. Como eram discentes de estratos sociais menos favorecidos, caso não participassem do programa, é provável que tivessem poucas oportunidades de acesso a esses dispositivos culturais.

É preciso considerar que todos os instrumentos utilizados são de autorrelato. Ou seja, as informações são fruto das percepções das crianças e isso é uma das limitações do estudo. Em novas pesquisas, é importante que sejam incluídas estratégias para o levantamento de dados junto às familias, professores das escolas e educadores dos programas a fim de complementar os dados coletados com os discentes. Novas investigações devem ser realizadas em outros contextos contemplando, também, escolas privadas a fim de comprovar ou não as hipóteses apuradas na presente oportunidade.

\section{Referências}

Andrada, E. G. C. de., Rezena, B. D. S., Carvalho, G. B. de, \& Benetti, I. C. (2008). Fatores de risco e proteção para a prontidão escolar. Psicologia: Ciência e Profissão, 28(3), 536-547. http://dx.doi.org/10.1590/S141498932008000300008

Batista, C. B. \& Andrade, V. S. F. de. (2010). Educação integrada e espaços de aprendizagens: diálogos entre escola e projeto social. Gerais: Revista Interinstitucional de Psicologia, 3(1), 2-11.

Brandão, A. P. \& Lordelo, L. da R. (2017). Significados de atividades extracurriculares para crianças bailarinas. Psicologia Escolar e Educacional, 21(3), 477-486. http:// dx.doi.org/10.1590/2175-3539/2017/021311178

Brasil. Ministério da Educação. (2016). Portaria Nº 1.144, de 10 de outubro de 2016, que institui o Programa Novo Mais Educação, que visa a melhorar a aprendizagem em lingua portuguesa e matemática no ensino fundamental. Brasília, DF: Diário Oficial da União.

Brasil. Ministério da Saúde. Conselho Nacional de Saúde. (2012). Resolução no 466, de 12 de Dezembro de 2012. Brasília, DF: Diário Oficinal da União.

Brasil. (2007). Portaria Normativa Interministerial ${ }^{\circ} 17$, de 24 de abril de 2007. Institui o Programa Mais Educação que visa fomentar a educação integral de crianças, adolescentes e jovens, por meio do apoio a atividades sócio-educativas no contraturno escolar. Brasilia, DF: Diário Oficial da União. 
Carvalho, M. P. de, Senkevics, A. S., \& Loges, T. A. (2014). O sucesso escolar de meninas de camadas populares: qual o papel da socialização familiar? Educação e Pesquisa, 40(3), 717-734. http://dx.doi.org/10.1590/ S1517-97022014091637

Carvalho, M. P. de., Loges, T. A., \& Senkevics, A. S. (2016). Familias de setores populares e escolarização: acompanhamento escolar e planos de futuro para filhos e filhas. Estudos Feministas, 24(1), 81-99. http://dx.doi. org/10.1590/1805-9584-2016v24n1p81

Castro, A. de \& Lopes, R. E. (2011). A escola de tempo integral: desafios e possibilidades. Ensaio: Avaliação de Politicas Públicas Educacionais, 19(71), 259-282. http:// dx.doi.org/10.1590/S0104-40362011000300003

Cavaliere, A. M., Coelho, L. M., \& Maurício, L. V. (2013). Implicações da Ampliação do Tempo Escolar nas Relações entre Familia e Escola. In G. Romanelli, M. A. Nogueira, M., \& N. Zago (Orgs.), Familia \& Escola: novas perspectivas de análise (pp. 257-277). Petrópolis, RJ: Vozes.

Coelho, L. M. C. da C. \& Mauricio, L. V. (2016). Sobre o tempo e conhecimentos praticados na escola de tempo integral. Educação e Realidade, 41(04), 1095-1112. http:// dx.doi.org/10.1590/2175-623660673.

Coelho, L. M. C. da C. (2009). História(s) da educação integral. Em Aberto, 22(80), 83-96.

D'Avila-Bacarji, K. M. G., Marturano, E. M., \& Elias, L. C. dos S. (2005). Suporte parental: um estudo sobre crianças com queixas escolares. Psicologia em Estudo, 10(1), 107-115

Giacomoni, C. H. \& Hutz, C. S. (2008). Escala multidimensional de satisfação de vida para crianças: estudos de construção e validação. Estudos de Psicologia, 25(1), 25-35. http://dx.doi.org/10.1590/S0103166X2008000100003

Giacomoni, C. H., Souza, L. K. de, \& Hutz, C. S. (2016). Você é feliz? Autopercepção da felicidade em crianças. Psicologia da Educação, 43, 13-22. https://dx.doi. org/10.5935/2175-3520.20160002

Gil, A. C. (2002). Como elaborar projetos de pesquisa. São Paulo, SP: Editora Atlas.

Gilman, R., Meyers, J., \& Perez, L. (2004). Structured extracurricular activities among adolescents: findings and implications for school psychologists. Psychology in the School, 41(1), 31-41.

Lahire, B. (2004), Sucesso Escolar nos Meios Populares. As Razões do Improvável. São Paulo, SP: Editora Ática.

Matias, N. C. F. (2019). Elaboração de uma Escala de Envolvimento em Atividades Extracurriculares para Crianças. Ciências Psicológicas,13(2), 235-248. http:// dx.doi.org/10.22235/cp.v13i2.1879

Matias, N. C. F. (2018). Relações entre Nivel Socioeconômico, Atividades Extracurriculares e Alfabetização. Psico-USF, 23(3), 567-578. http://dx.doi.org/10.1590/1413$\underline{82712018230314}$
Matias, N. C. F. \& Teodoro, M. L. M. (2018). Adaptação do inventário do clima familiar para crianças (ICF-C). Avaliação Psicológica, 17(1), 20-27. https://dx.doi. org/10.1568g/ap.2017.1701.03.13059

Nascimento, C. R. R., \& Trindade, Z. A (2010). Criando meninos e meninas: investigação com famílias de um bairro de classe popular. Arquivos Brasileiros de Psicologia, 62(2), 187-200.

Oberle, E., Schonert-Reichl, K. A., \& Zumbo, B. D. (2011). Life Satisfaction in Early Adolescence: personal, neighborhood, school, family, and peer influences. Journal Youth Adolescence, 40, 889-901. http://dx. doi. org/10.1007/s10964-010-9599-1

Osti, A. (2016). Contexto familiar e o desempenho de estudantes do $5^{\circ}$ ano de uma escola no interior de São Paulo. Educação Temática Digital, 18(2), 369-383. http:// dx.doi.org/10.20396/etd.v18i2.8637508

Pierce, K. M., Bolt, D. M., \& Vandell, D. L. (2010). Specific features of after-school program quality: associations with children's functioning in middle childhood. American Journal Community Psychology, 45, 381-393. http:// dx.doi.org/10.1007/s10464-010-9304-2

Resende, T. de F., Canaan, M. G., Reis, L. da S., Oliveira, R. A. de., \& Souza, T. C. S. de (2018). Dever de casa e relação com as familias na escola de tempo integral. Educação e Realidade, 43(2), 435-456. http://dx.doi. org/10.1590/2175-623662458

Ribeiro, R., Ciasca, S. M. \& Capelatto, I. V. (2016). Relação entre recursos familiares e desempenho escolar de alunos do $5^{\circ}$ ano do ensino fundamental de escola pública. Revista Psicopedagogia, 33(101), 164-174.

Santos, A. M., Neto, F. R., \& Pimenta, R. A. (2013). Avaliação das habilidades motoras de crianças participantes de projetos sociais/esportivos. Motricidade, 9(2), 50-60. http://dx.doi.org/10.6063/motricidade.g(2).2667

Schünemann, H. E. S. \& Zukowski-Tavares, C. (2018). Estratégias das familias populares de apoio à escolarização. Revista Eletrônica de Educação, 12(1), 169-183. http://dx.doi.org/10.14244/198271992095

Senkevics, A. S., \& Carvalho, M. P. de. (2015). Casa, rua, escola: gênero e escolarização em setores populares urbanos. Cadernos de Pesquisa, 45(158), 944-968. http:// dx.doi.org/10.1590/198053143364

Silva, J. A. de A. da. \& Silva, K. N. P. (2014). Analisando a concepção de educação integral do governo Lula/ Dilma através do programa Mais Educação. Educação em Revista, 30(01), 95-126. http://dx.doi.org/10.1590/ S0102-46982014000100005

Silva, M. G. Q. da. \& Ehrenberg, M. C. (2017). Atividades culturais e esportivas extracurriculares: influência sobre a vida do discente. Pro-posições, 18(1), 15-32. http:// dx.doi.org/10.1590/1980-6248-2015-0055

Silva, S. D. B., Monteiro, E. F., Pontes, F. A. R. Magalhães, C. M. C., \& Silva, S. S. da C. (2012). Brincadeiras de rua em Belém-PA: uma análise de gênero e idade. Psicologia: teoria e prática, 14(2), 28-42. 
Soares, A. J. G., Brandolin, F., \& Amaral, D. P. do. (2017). Desafios e dificuldades na implementação do programa Mais Educação: percepção dos atores da escola. Educação e Realidade, 42(3), 1059-1079. http://dx.doi. org/10.1590/2175-623660490

Soares, T. M., Riani, J. de L. R. de, Nóbrega, M. C., \& Silva, N. F. da. (2014). Escola de Tempo Integral: resultados do projeto na proficiência dos alunos do Ensino Fundamental das escolas públicas da rede estadual de Minas Gerais. Ensaio: Avaliação e Politicas Públicas em Educação, 22(82), 111-130. https://dx.doi.org/10.1590/ S0104-40362014000100006

Vandell, D. L., Larson, R. W., Mahoney, J. L., \& Watts, T. W. (2014). Children's organized activities. In M. H. Bornstein, T. Leventhal, \& R. M. Lerner. (Eds.), Handbook of child psychology and developmental science: ecological settings and processes in developmental systems, 7(4) (pp. 305-344). New York, NY: Wiley.

\section{Neyfsom Carlos Fernandes Matias}

Doutor em Psicologia pela Universidade Federal de Minas Gerais (UFMG), em Belo Horizonte, MG, Brasil; professor do Programa de Pós-Graduação em Psicologia e do Departamento de Psicologia da Universidade Federal de São João del-Rei (UFSJ), em São João del-Rei, MG, Brasil.

\section{Endereço para correspondência}

Neyfsom Carlos Fernandes Matias

Universidade Federal de São João del Rei/ Departamento de Psicologia

Praça Dom Helvécio, 74, sala 2.20

36301-160

São João del-Rei, MG, Brasil 